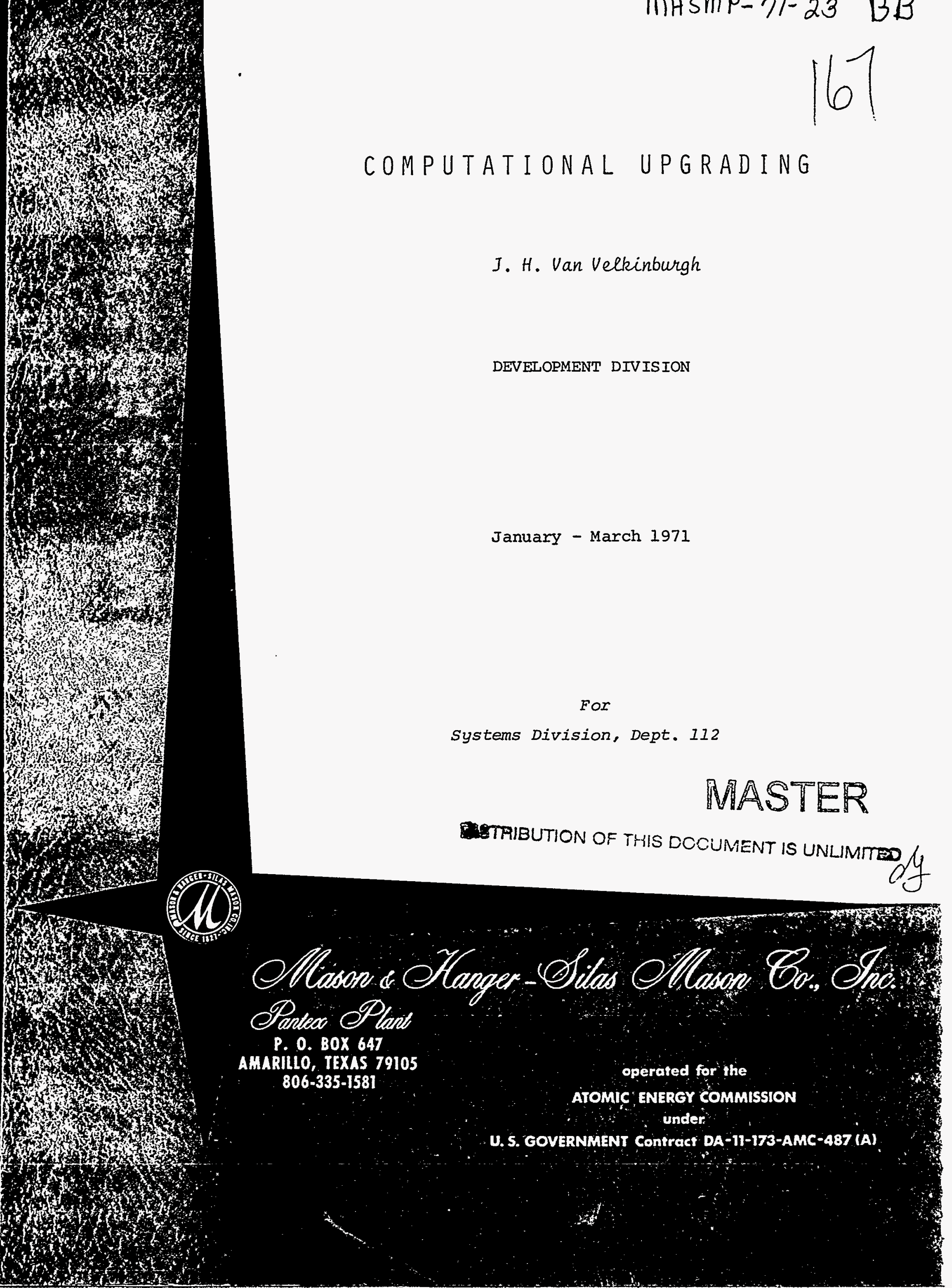




\section{HOTICE}

This report was prepared as an account of work sponsored by the United Stafes Government. Neither the United Staies nor the United States Atomic Energy Commission, nor their employees, nor any of their contractors, sobcontractors, or their employees, makes any warranty, express or implied, or assumes any legal liability or responsibility for the accuracy, completeness or usefulness of ony information, apparatus, product or process disclosed, or represents that its use would not infringe privately-owned rights. 


\section{DISCLAMIER}

Portions of this document moy be illegibie in electronic image products. Images are produced from the best available original document. 


\title{
COMPUTATIONAL UPGRADING
}

\begin{abstract}
Additions to our data acquisition and reduction facilities and other nonprogramming endeavors are discussed.

Computer codes designed to aid in the analys is and interpretation of quantitative data which were written or modified this period are discussed.
\end{abstract}

\section{DISCUSSION}

The acquisition proposal (per AECM Chapter 1801) for the DEC PDP 12/30 Advanced LINC System was completed. The PDP 12/30 wi11 provide data acquisition and computational support for the development and research activities pertaining to the thermal properties of high explosives and related materials. The acquisition proposal was started on the required channels for approval and purchase.

The justification for the purchase of the IBM Model 029 keypunch to be used in conjunction with the Grant optical comparator was rewritten in the AECM 1801 format to comply with the requirements for the procurement of ADP equipment. The acquisition proposal was submitted for approval.

The Wang Model 702 plotting output writer was delivered this period. A number of plotting and data output routines have been written. These include, among others, polynomial regression codes with plots and output, non-linear regression codes with plots and output, plotting routines and data tabulation routines. Many of the plots and output routines are in a finished format suitable for inclusion in reports. Figs. 1 and 2 are typical output from the Wang 702 output writer.

A paper tape reader was requisitioned this period for the Wang 700 system.

Final preparations were completed for the installation of the CDC 3600 . The building modifications were completed and environmental control systems installed. The wiring of the various component modules was tentatively completed pending final checkout by Control Data personnel. The entire system should be ready to operate the first week of the next period. The COSMIC program library, operated by the University of Georgia, was searched for applications programs which may be of interest or use. Table $I$ is a list of the programs and documentation initially requested. The COSMIC 1 ibrary will be reviewed periodically for other possible applications programs. 


\title{
COMPUTATIONAL UPGRADing
}

\author{
J. H. Van Velkinburgh
}

DEVELOPMENT DIVISION

This project concerns the upgrading of computer technology to a level commensurate with other technologies at hand, to provide a meaningful link between Development and the Data Center, and to assist personnel in their computational needs.

January, February, March 1971

Systems Division, Dept. 112 
STANDARD ERROR OF ESTIIATE

SUM OF SRCARED RESIDLALS
CORRELATION COEFFICIENT

$Y=A 1+A 2 * X+A 3 * \exp (A 4 \star X)$

$\begin{array}{lr}A 1 & =\quad 3.905464377 \\ A 2 & \quad 6.784636206 \\ A 3 & -3.972125109\end{array}$

$X$ ARRAY

onononono .431800000 .315800000 $1.74260000 n$ 2.633000000 3.087900000 3.535500010 $4.50580000 n$ 4.987500000
$5.4748000 n 0$ 5.975400000 6.537900000 7.065200000 7.603501000 8.744400000 9.336000000 i ARRAY

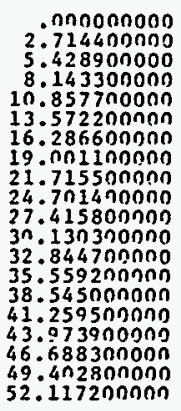

.046358302 . 932236383

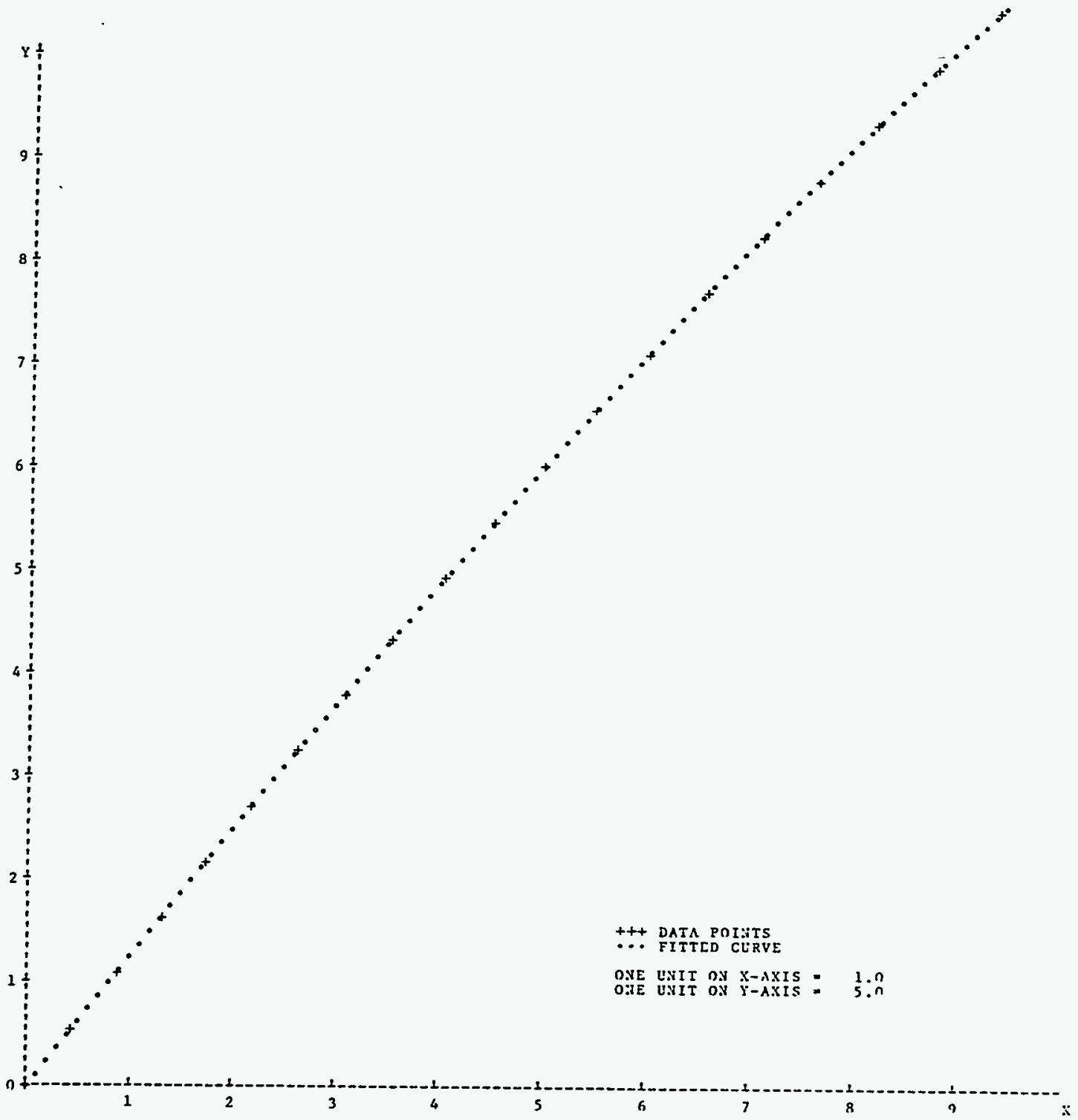

Fig. 1. Sample Output from hang Plotter 


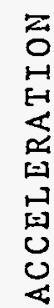

芒

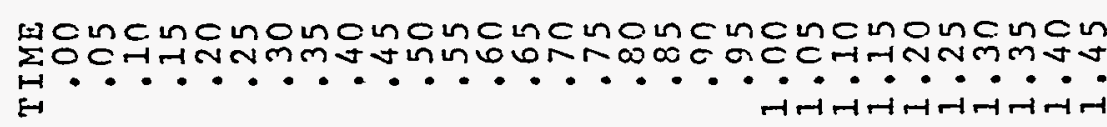
HOO E-

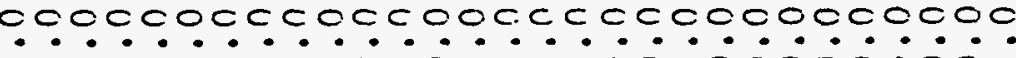

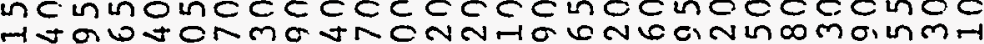

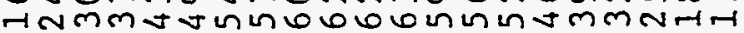

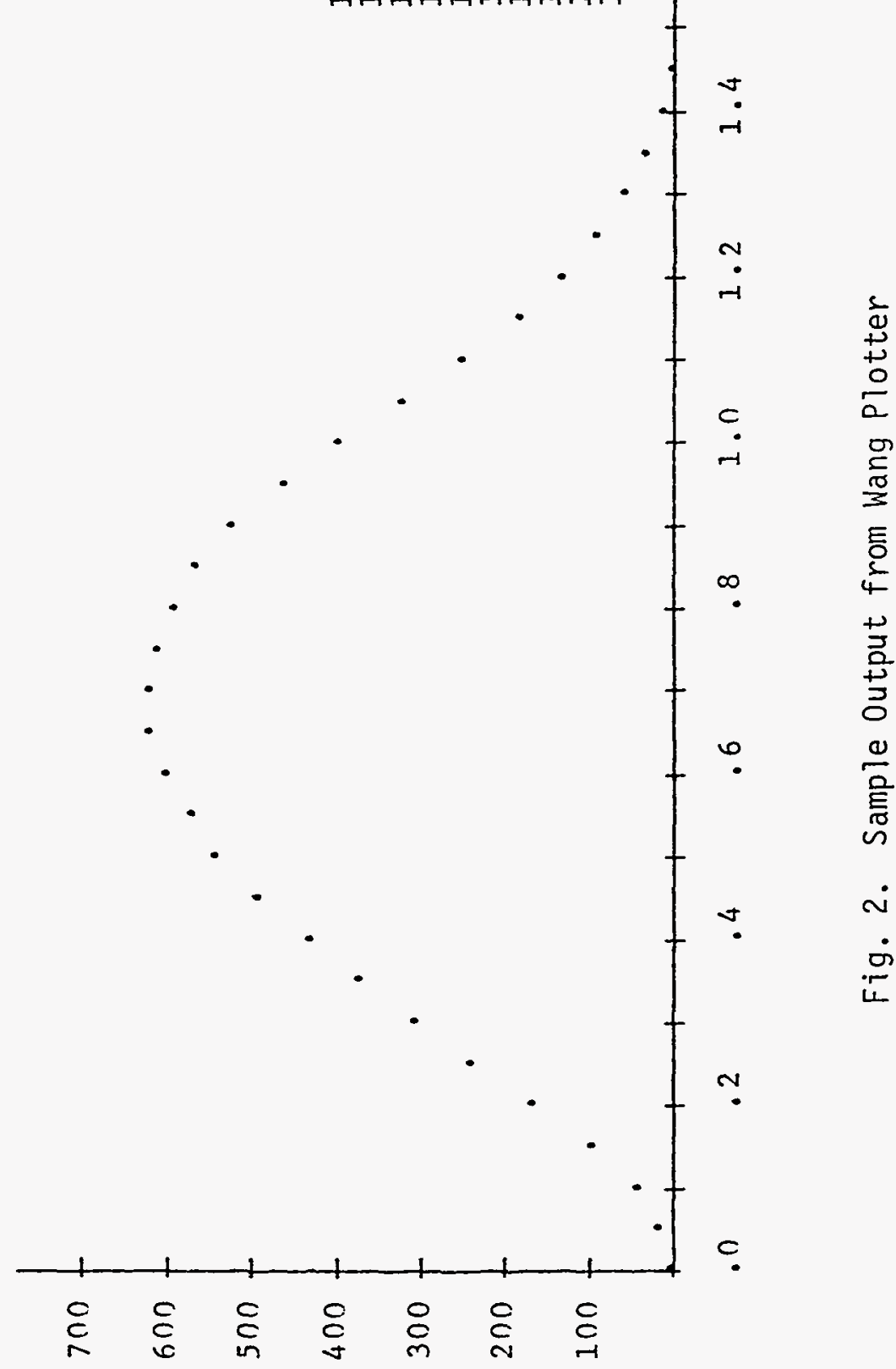

BB-3 
Table I. Computer Programs Requested from COSMIC

Program Name

TOODY II

WONDY

WONDY II I

TRUMP

TRUMP/XB2

SWAP-9

MFS -14285

GSC -10362

ALO-00223

NPO 11473

NASAP

BROOT

VERGE
Description

A computer program for calculating problems of motion in two dimensions

A computer program for calculating problems of motion in one dimension

An enlarged and more generalized version of WONDY

A computer program for transient and stead-state temperature distributions in multi-dimensional systems

Materials constants library and data compilation program for TRUMP

A computer program for analyzing stress or shock waves in multi-dimensional systems

Techniques for polynomial curve fits where the degree of the polynomial is equal to or greater than the number of data points

A computer program for calculating surface area and pore size of materials from data obtained from the BET gas adsorption apparatus

A computer program for performing calculations on data obtained from an isoperibol calorimeter

A computer program for the reduction of mass spectrometer data

A computer program to aid in the analys is of electrical network systems

A computer program to find roots or solutions of equations

A computer program to accelerate the convergence of iterative processes 
A series of Wang 700 programs was written to aid in the analys is of streak camera data generated by $C$. E. Canada and L. D. Hanes in their study of a Sandia-developed pressure gage. Programs written included data normalization routines, non-linear equation solvers to find particle velocities and the angles of shock wave emergence, Hugoniot equation solvers and modifications to plotting routines for data presentation.

A major portion of the data analys is and FORTRAN programming effort this period was directed toward the Aquarium Sphere Tests. As mentioned last period, it was thought that useful information about spherical detonation could be obtained by performing calculations on the radial expansion-time data numerically. This would alleviate limitations imposed upon calculated results which might be due to analytical curve fitting.

Toward this end, then, a computer code was written to evaluate first and second derivatives (velocities and accelerations) numerically. The normal numerical derivative formulas demand that when approximating $d Y / d X$, the $Y$ values be evenly spaced. The technique employed im the present programs used numerical derivative algorithm with linear interpolation to handle data unequally spaced with respect to distance. Computer runs were made and plots generated for several explosives. Photographic reproductions of some of the results are given in Figs. 3 through 6 . Results were not as illuminating as had been hoped for. Differences in velocity histories and acceleration histories be tween different explosive compositions were of such magnitude so as to make any distinction be tween them difficult.

Besides trying to observe differences in performance among a series of explosives, a major purpose of this computer code was to observe bumps or a ringing effect in the velocity history. These perturbations and their physical causes were discussed at length last period. If these perturbations were present in the velocity history, but were of an amplitude that they might be overlooked, they would be magnified to such an extent in the acceleration history so as to be unmistakable. This magnification, due to the differentiation process, has been discussed in previous periods. No perturbations were observed in the acceleration histories studied. This was interpreted to mean that the change in pressure as the reflected rarefaction passes the main shock is so weak that no observable event occurs or that this second shock has not yet reached the main shock in the interval of time recorded on the streak camera record. The latter interpretation is probably correct. The theoretical aspects of this second wave phenomenon, discussed last period, state that the first bump will occur at approximately seven spherical charge radii. This is about $1-1 / 4$ to $1-1 / 3$ the maximum radial expansion observed on any record. Results from this study therefore were somewhat inconclusive.

A different approach to the problem of separating explosives on the basis of performance as measured in the Aquarium Sphere Test* was taken. This involved calculating the rate at which work was being done on the water by the expanding spherical shock wave. Neglecting energy losses such as those due to production of heat in the water by the passing of the shock wave, etc., the rate of

*Under study by I. B. Akst and J. K. Rigdon 
energy within the spherical volume enclosed by the expanding shock front at any one time is the negative of the rate at which work is being done by the shock wave on the water. The computer code was written to calculate this rate of work. Results of these calculations are shown as plots of the $d E / d t$ history for several explosives in Fig. 7. These plots show these explosives as distinctly different in their ability to perform work. This is the first time in this endeavor that differences in performance have been readily observable. The plots show, for instance, that PBX 9404 very quickly gives up its workproducing energy while TNT loses its energy at a much slower rate.

FUTURE WORK; COMMENTS; CONCLUSIONS

Future work on this project will be directed toward the Aquarium Sphere Tests especially in the area of $\mathrm{dE} / \mathrm{dt}$ histories in relation to explosives performance. 

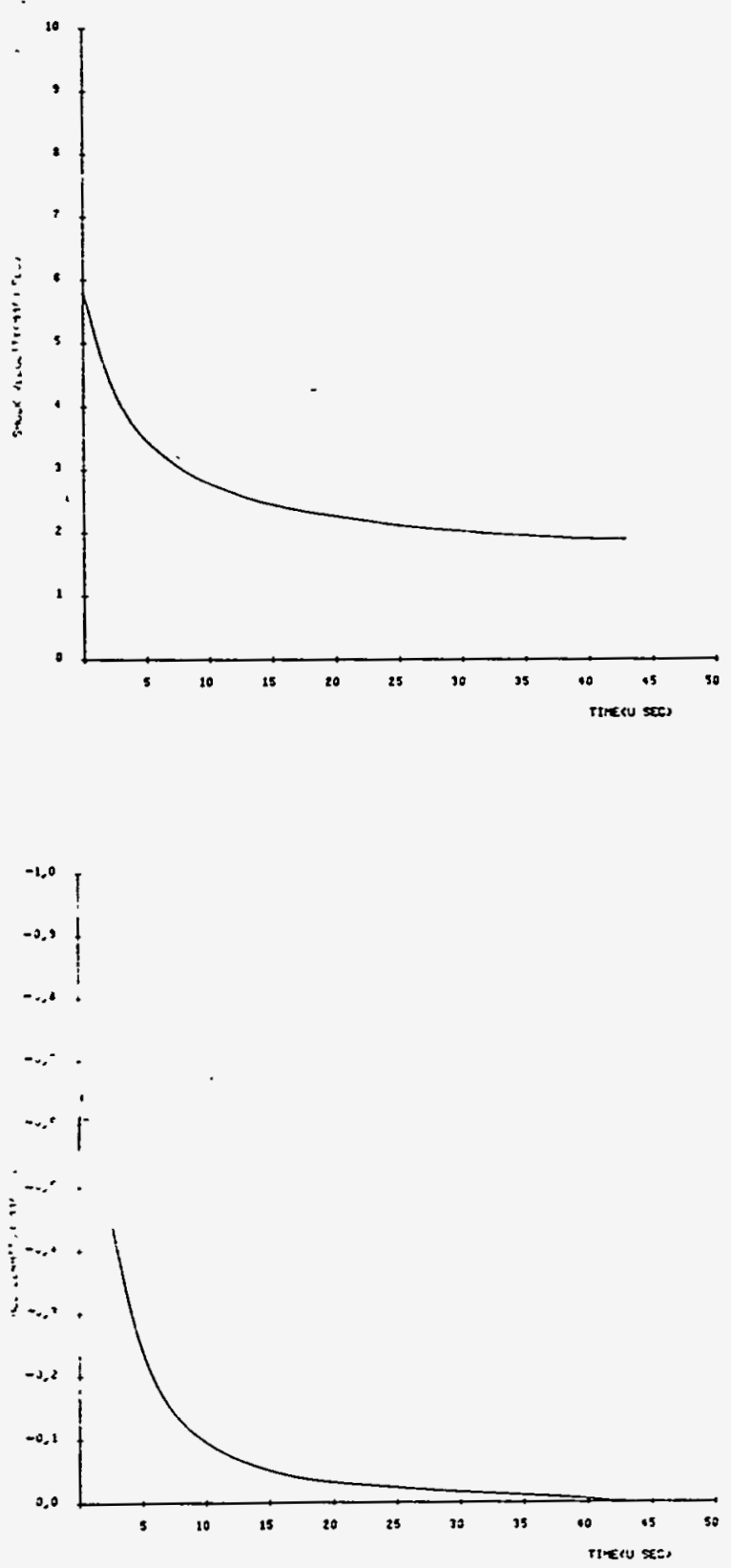

Fig. 3. Numerical First and Second Derivatives for 3-cm Radius RX-04-DS Sphere 

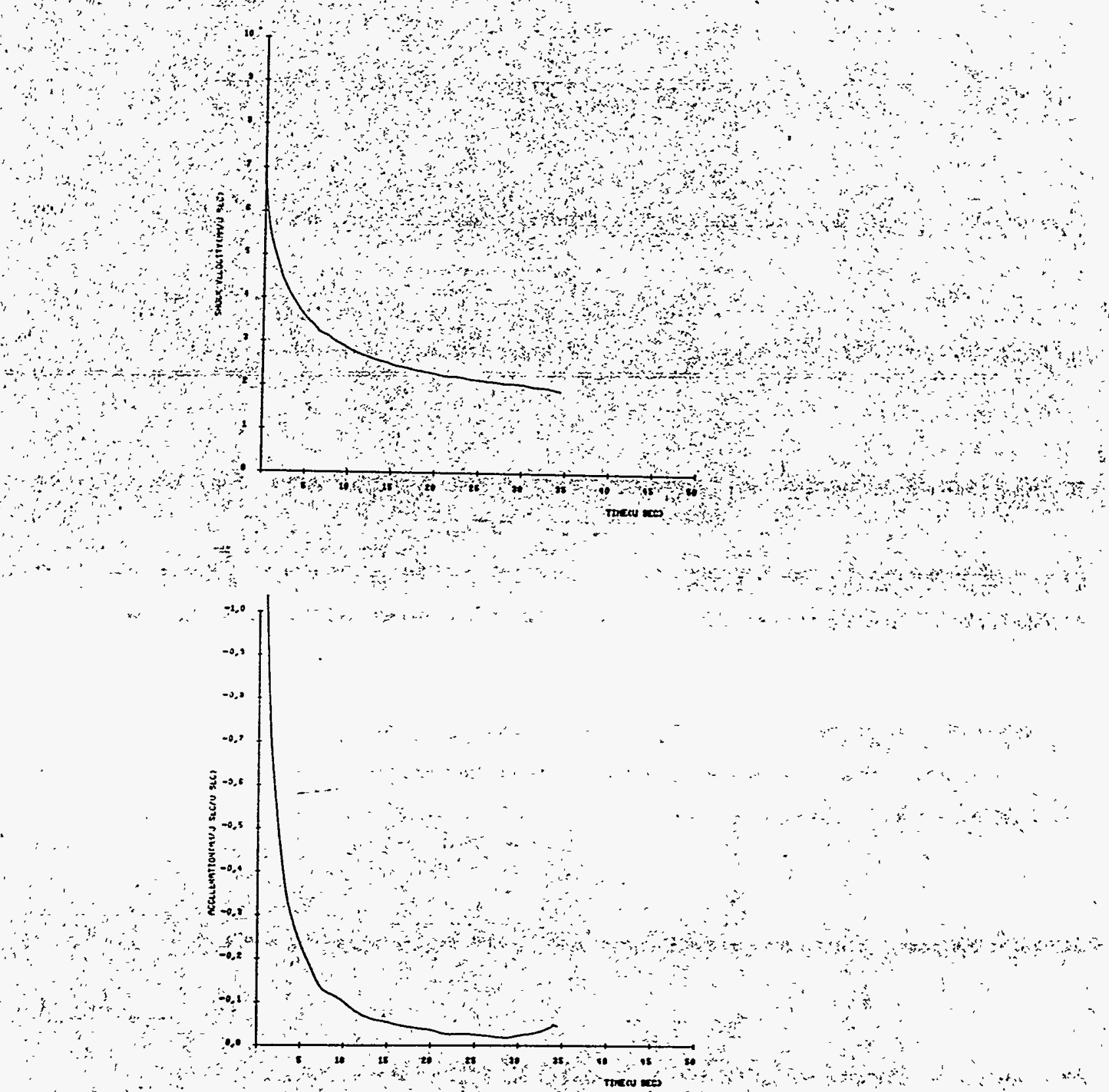

Fig 4 Numerical Forst and Secoñd Derivatives on for 3-cm Radius PBX 9404 Sphere

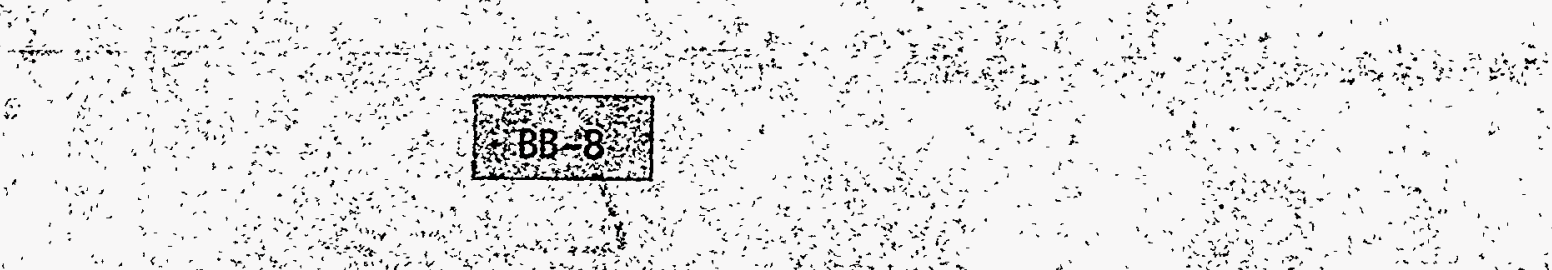

An 

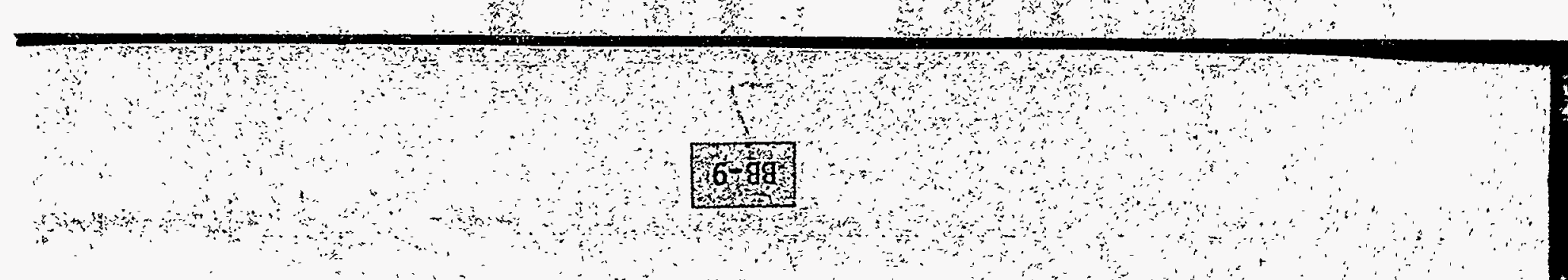

söloyds $0-\angle 0-\times 7$ snipey us- $\left.\varepsilon^{2} 10\right\rfloor$

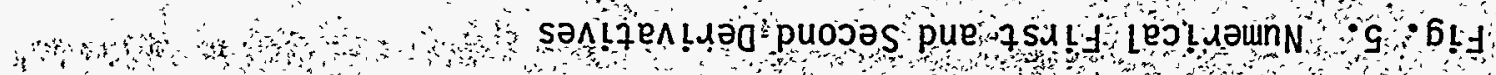

$\therefore \quad \ldots$

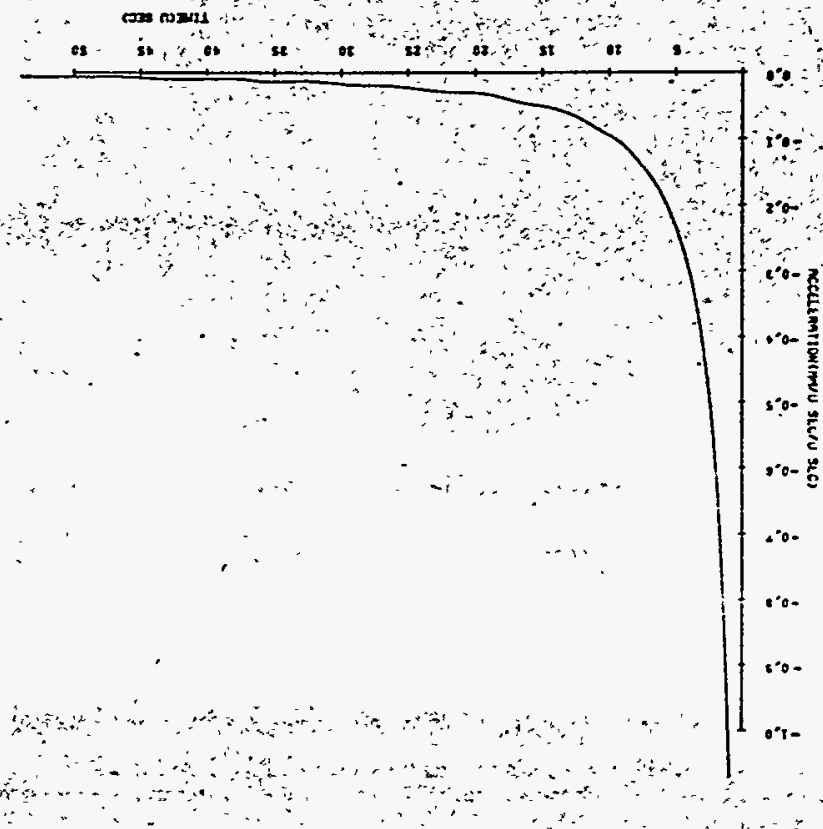

and

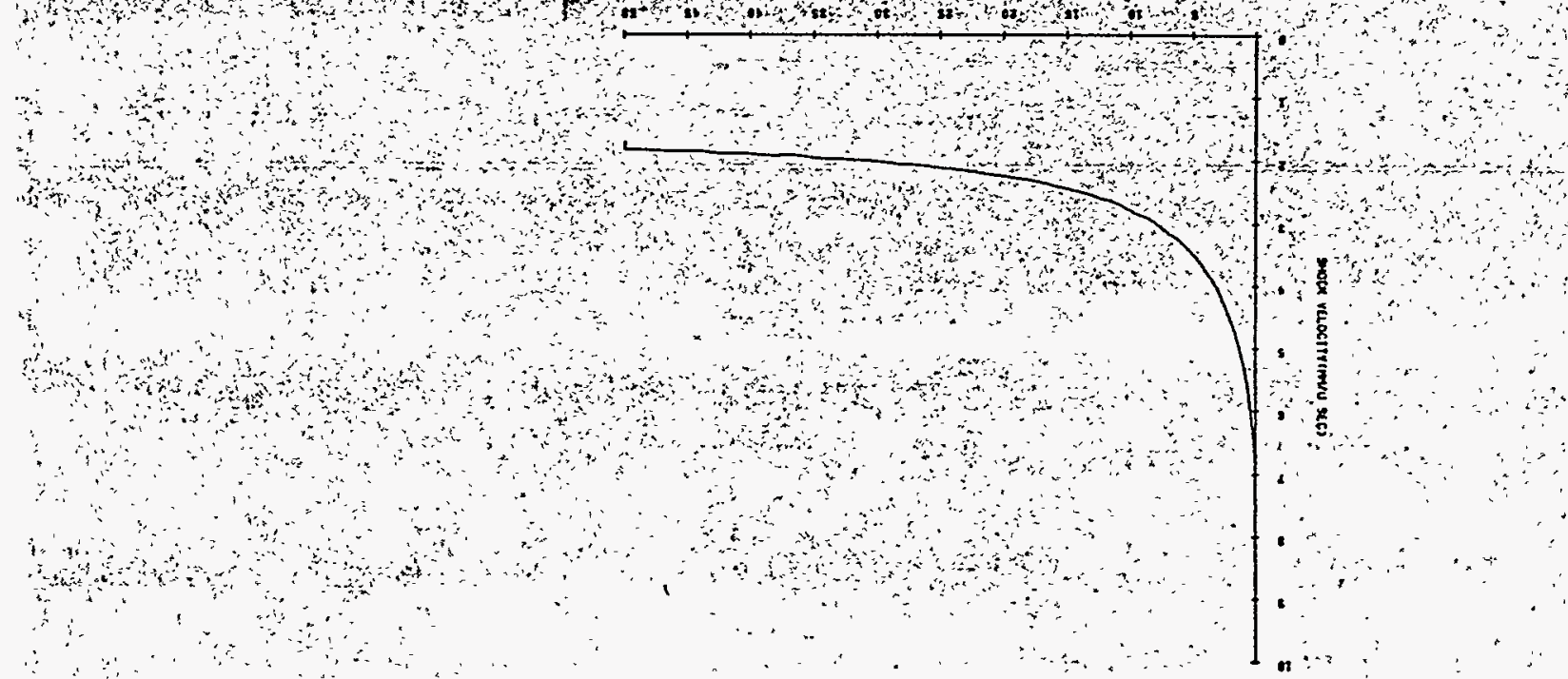





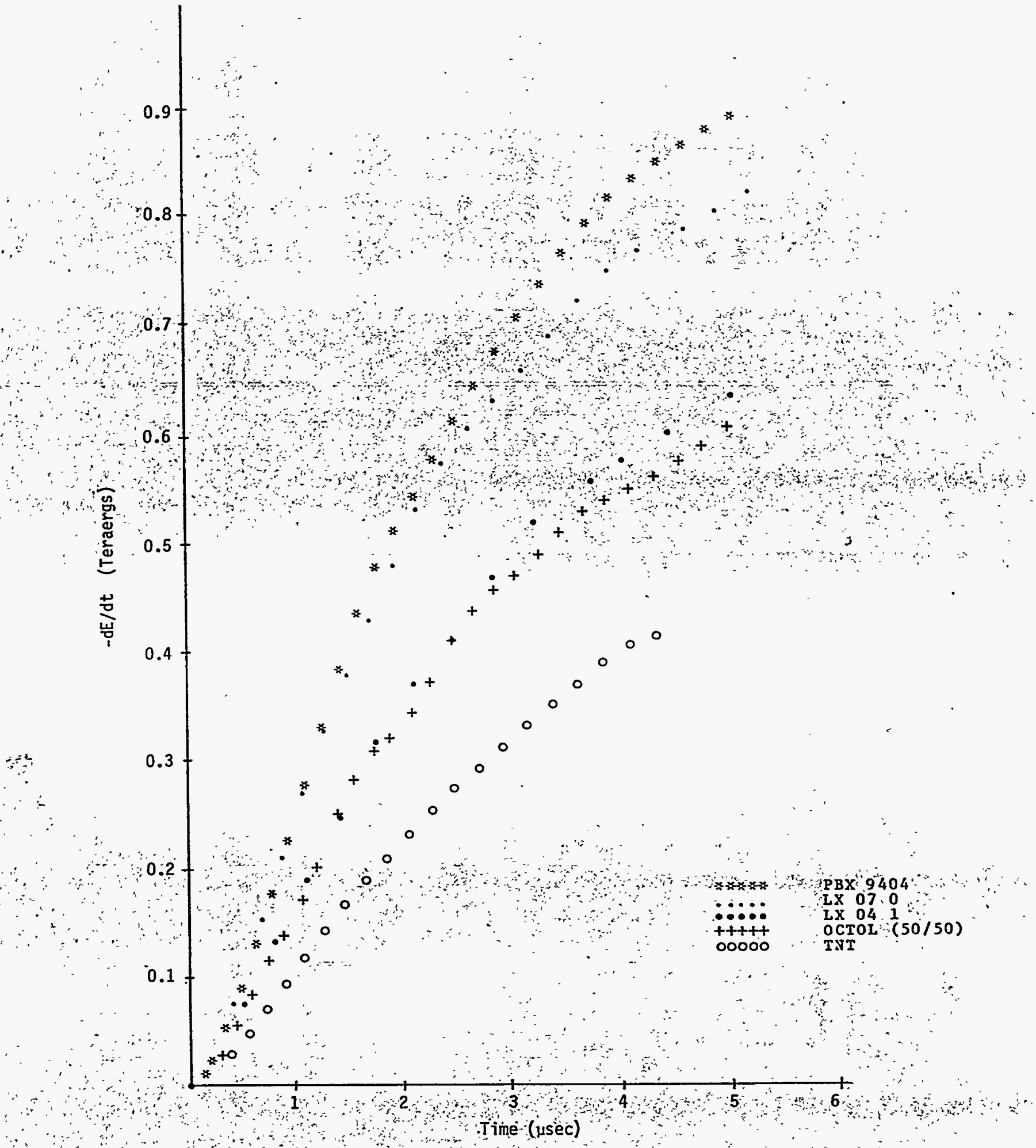

Fig. 7. dE/dt Curves for Five Explosives in 3 -on Radius Geometry 